\title{
Crack Growth Analysis of Solid Oxide Fuel cell Electrolytes
}

\author{
Final Topical Report
}

Jan 2002 - Sept 2002

Principal Authors:

Prof. S. Bandopadhyay

Dr. N. Nagabhushana

Re-Issued: October 2003

DOE Award \# DE-FC26-01NT41248

School of Mineral Engineering, University of Alaska Fairbanks

Fairbanks, AK 99775 


\section{DISCLAIMER}

This report was prepared as an account of work sponsored by an agency of the United States Government. Neither the United States Government nor any agency thereof, nor any of their employees, makes any warranty, express or implied, or assumes any legal liability or responsibility for the accuracy, completeness, or usefulness of any information, apparatus, product, or process disclosed, or represents that its use would not infringe privately owned rights. Reference herein to any specific commercial product, process, or service by trade name, trademark, manufacturer, or otherwise does not necessarily constitute or imply its endorsement, recommendation, or favoring by the United States Government or any agency thereof. The views and opinions of authors expressed herein do not necessarily state or reflect those of the United States Government or any agency thereof 


\begin{abstract}
Defects and Flaws control the structural and functional property of ceramics. In determining the reliability and lifetime of ceramics structures it is very important to quantify the crack growth behavior of the ceramics. In addition, because of the high variability of the strength and the relatively low toughness of ceramics, a statistical design approach is necessary. The statistical nature of the strength of ceramics is currently well recognized, and is usually accounted for by utilizing Weibull or similar statistical distributions. Design tools such as CARES using a combination of strength measurements, stress analysis, and statistics are available and reasonably well developed. These design codes also incorporate material data such as elastic constants as well as flaw distributions and time-dependent properties. The fast fracture reliability for ceramics is often different from their time-dependent reliability. Further confounding the design complexity, the time-dependent reliability varies with the environment/temperature/stress combination. Therefore, it becomes important to be able to accurately determine the behavior of ceramics under simulated application conditions to provide a better prediction of the lifetime and reliability for a given component.

In the present study, Yttria stabilized Zirconia (YSZ) of $9.6 \mathrm{~mol} \%$ Yttria composition was procured in the form of tubes of length $100 \mathrm{~mm}$. The composition is of interest as tubular electrolytes for Solid Oxide Fuel Cells. Rings cut from the tubes were characterized for microstructure, phase stability, mechanical strength (Weibull modulus) and fracture mechanisms. The strength at operating condition of SOFCs $\left(1000^{\circ} \mathrm{C}\right)$ decreased to $95 \mathrm{MPa}$ as compared to room temperature strength of $230 \mathrm{MPa}$. However, the Weibull modulus remains relatively unchanged. Slow crack growth (SCG) parameter, $\mathrm{n}=17$ evaluated at room temperature in air was representative of well studied brittle materials. Based on the results, further work was planned to evaluate the strength degradation, modulus and failure in more representative environment of the SOFCs.
\end{abstract}




\section{TABLE OF CONTENTS}

EXECUTIVE SUMMARY

INTRODUCTION

TASK 1.2: $\quad$ Crack Growth Parameters 


\section{LIST OF GRAPHICAL MATERIALS}

Figure 1: a) Optical micrograph of the thermally etched YSZ indicating uniform grain size.

b) Higher magnification of a single grain of the thermally etched YSZ indicating closed porosity in the grain

Figure 2: $\quad$ X-ray analysis of the YSZ tube indicating full stabilization of the cubic phase.

Figure 3: C-ring test configuration for strength evaluation of YSZ tubes

Figure 4: Weibull plot for strength evaluation of YSZ tubes at room temperature

Figure 5: $\quad$ C-ring Fracture Strength-Stress Rate Diagram. a) Plot of strength vs. stress rate and b) Log (Fracture Strength) versus Log (Stress Rate)

Figure 6 Fracture surfaces examined under SEM indicating transgranular fracture. At low stress rates ( $a$ and $b$ ), higher incidence of micro-cleavage in grains in visible. At higher stress rates $(50 \mathrm{MPa} / \mathrm{s})$, grains are relatively smoother with reduced micro-cleavage planes.

Fig. 7: Weibull plots of C-ring fracture strength at room temperature and at $1000^{\circ} \mathrm{C}$ in air. 


\section{Executive Summary}

Increasing demand for clean fuel and raising global concerns on environmental issues in burning of fossil fuels has fuelled the search for alternate source of clean energy. Fuel cells represent an important opportunity to utilize fossil fuels in an efficient and environmentally friendly manner. Fuel cells produced in small expandable modules and manufactured cheaply by taking advantage of economies of production are well suited to meet a growing worldwide demand for energy. The modules produced could be made scalable allowing application of capital in smaller incremental amounts as electrical power demands increase.

Solid Oxide Electrolyte Fuel Cells (SOFC) has been widely identified as one such possible source of clean energy. Although for these fuel cells, the preferred fuel is hydrogen, it has been shown that more commonly available fuels such as natural gas could also be used. Importantly, controlled oxidation of fuels such as natural gas can be carried out in the cell to produce chemical by-products to acts as feeders for the chemical industries.

Solid-oxide fuel cells were once considered the most technically challenging fuel cell type. However, many recent breakthroughs in ceramic materials, fuel cell design, and manufacturing technology have changed this view. Advances in ceramic thin film processes enabling the development of high power density electrode supported cells; compact fuel processing technology; and adoption of manufacturing methods developed in related industries such as the semiconductor industry are enabling the quick maturing of the technology and making the solid oxide fuel cells a viable option for mass applications in the future. A solid-oxide fuel cell is highly efficient. Even without cogeneration a solid-oxide fuel cell system can be twice as efficient as competing technologies due to the direct conversion of fuel to electrical power. With thermal recovery, system efficiency could reach as high as $85 \%$. In addition, SOFC systems are clean. They generate no solid wastes, and due to the higher efficiency and the replacement of fossil fuel combustion with a lower temperature electrochemical conversion, fuel cells significantly lower emissions of nitrogen compounds and greenhouse gases.

One of the most common fuel cells presently in use is the Zirconia based cell. Fully stabilized and Yttria doped Zirconia (YSZ) ceramics, have been successfully used as fuel cell for about 10,000 hours. The fuel cells are typically in the form of thin walled tubes with fuel passing on one surface and air on the other. However, as all ceramics YSZ are by nature brittle and are prone to catastrophic failure. The high temperature and harsh environment make the ceramics more susceptible to slow crack growth and thus exhibit time-dependent failure. While this behavior is relatively simplistic (in reality it is complex) in bulk and regular bar test specimens, they tend to be more complex when irregular components (such as tubes) are involved. Predictions of, and improvements to, the reliability of components and systems are thus to be developed by combining the approaches of materials science and mathematical reliability analysis 


\section{Introduction}

Fuel cells are electrochemical devices that convert the chemical energy of a reaction directly into electrical energy. The basic physical structure or building block of a fuel cell consists of an electrolyte layer in contact with a porous anode and cathode on either side. In a typical fuel cell, gaseous fuels are fed continuously to the anode (negative electrode) compartment and an oxidant (i.e., oxygen from air) is fed continuously to the cathode (positive electrode) compartment; the electrochemical reactions take place at the electrodes to produce an electric current. The fuel cell is thus an energy conversion device that theoretically has the capability of producing electrical energy for as long as the fuel and oxidant are supplied to the electrodes. In reality, degradation, primarily corrosion, or malfunction of components limits the practical operating life of fuel cells.

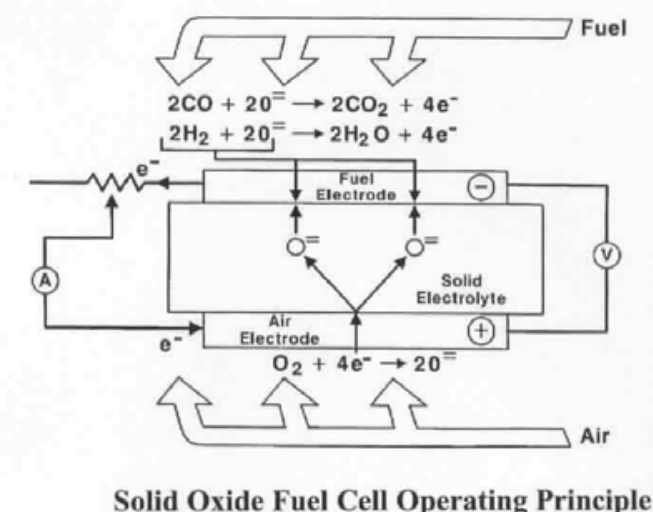

\section{Solid Oxide Fuel Cells}

Much of the recent effort in the development of fuel cell technology has been devoted to reducing the thickness of cell components while refining and improving the electrode structure and the electrolyte phase, with the aim of obtaining a higher and more stable electrochemical 
performance while lowering cost. Of the various fuel cell being developed Solid Oxide Fuel Cell (SOFC) the tubular design has been with the longest continuous development period and has since grown in recognition as a viable high temperature fuel cell technology. The operating temperature of $\sim 800^{\circ} \mathrm{C}$ allows internal reforming, promotes rapid kinetics with non-precious materials, and produces high quality byproduct heat for cogeneration or for use in a bottoming cycle. The high temperature of the SOFC, however, places stringent requirements on its materials. The development of suitable low cost materials and the low cost fabrication of ceramic structures are presently the key technical challenges facing SOFC's. However, since the electrolyte is solid, the cell can be cast into flexible shapes, such as tubular, planar, or monolith. The solid ceramic construction of the cell also alleviates any cell hardware corrosion problems characterized by the liquid electrolyte cells and has the advantage of being impervious to gas cross-over from one electrode to the other. The absence of liquid also eliminates the problem of electrolyte movement or flooding in the electrodes. At the temperature of presently operating SOFC's $\left(1000^{\circ} \mathrm{C}\right)$ fuel can be reformed within the cell and some of the rejected heat used to preheat the incoming process air. The high temperature of the SOFC has its drawbacks. There are thermal expansion mismatches among materials, and sealing between cells is difficult. The high operating temperature places severe constraints on materials selection and results in difficult fabrication processes. The two major impediments to the widespread use of fuel cells are: 1) high initial cost and 2) high-temperature cell endurance operation. These two aspects are the major focus of manufacturer's technological efforts. 
The solid-state character of all SOFC components means that, in principle, there is no restriction on the cell configuration and moreover, it is possible to shape the cell according to criteria such as overcoming design or application issues. Cells are presently being developed in different
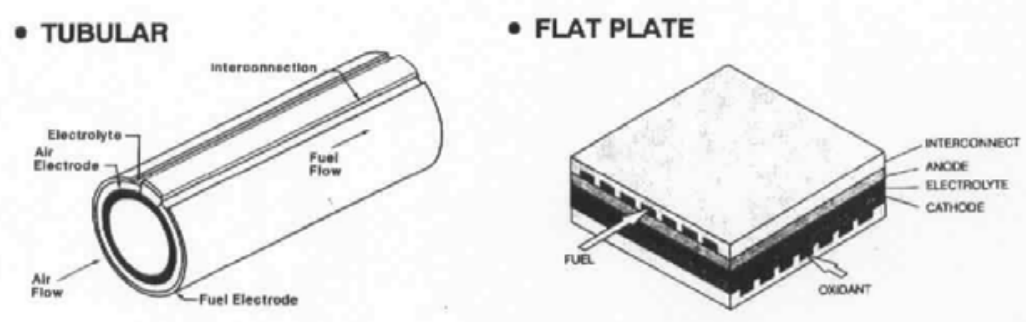

Solid Oxide Fuel Cell Designs at the Cathode

configurations; however the flat plate and the tubular design are emerging as the most popular designs.

A brief description of the materials currently used in the various cell components of the more developed tubular SOFC, and those that were considered earlier is presented. Because of the high operating temperatures of present SOFC's (approximately $1000^{\circ} \mathrm{C}$ ), the materials used in the cell components are limited by chemical stability in oxidizing and reducing environments, chemical stability of contacting materials, conductivity, and thermo-mechanical compatibility. These limitations have prompted investigations of developing cells with compositions of oxide and metals that operate at intermediate temperatures in the range of $650^{\circ} \mathrm{C}$.

Present SOFC designs make use of thin film concepts where films of electrode, electrolyte, and interconnect material are deposited one on another and sintered, forming a cell structure. Often various thin layers of refractory oxides suitable for the electrolyte, anode, and interconnection are deposited. This procedure has also been used to fabricate the solid electrolyte Yttria 
stabilized zirconia (YSZ). The anode consists of metallic Ni and an $\mathrm{Y}_{2} \mathrm{O}_{3}$ stabilized $\mathrm{ZrO}_{2}$ skeleton. The latter serves to inhibit sintering of the metal particles and to provide a thermal expansion coefficient comparable to those of the other cell materials

\section{Evolution of Cell Component Technology for Tubular Solid Oxide Fuel Cells}

\begin{tabular}{|c|l|}
\hline Component & \multicolumn{1}{|c|}{ Current Status } \\
\hline Anode & $\bullet \mathrm{Ni} / \mathrm{ZrO}_{2}$ cermet \\
& $\bullet$ Deposit slurry, EVD fixed \\
& $\bullet 12.5 \times 10^{-6} \mathrm{~cm} / \mathrm{cm} /{ }^{\circ} \mathrm{C}$ \\
& $\bullet \sim 150 \mathrm{~mm}$ thickness \\
& $\bullet 20-40 \%$ porosity \\
\hline Cathode & $\bullet$ Doped lanthanum manganite \\
& $\bullet$ Extrusion, sintering \\
& $\bullet \sim 2 \mathrm{~mm}$ thickness \\
& $\bullet 11 \times 10^{-6} \mathrm{~cm} / \mathrm{cm}^{\circ} \mathrm{C}$ expansion from room \\
& temperature to $1000^{\circ} \mathrm{C}$ \\
& $\bullet 30-40 \%$ porosity \\
\hline Electrolyte & $\bullet$ Yttria stabilized $\mathrm{ZrO}_{2}\left(8\right.$ mol $\left.\% \mathrm{Y}_{2} \mathrm{O}_{3}\right)$ \\
& $\bullet$ EVD d \\
& $\bullet 10.5 \mathrm{x} 10-6 \mathrm{~cm} / \mathrm{cm}{ }^{\circ} \mathrm{C}$ expansion from \\
& $\mathrm{RT}-1000^{\circ} \mathrm{C}$ \\
& $\bullet 30-40 \mu \mathrm{m}$ thickness \\
\hline Cell & $\bullet$ Doped lanthanum Chromite \\
Interconnect & $\bullet$ Plasma spray \\
& $10 \times 10-6 \mathrm{~cm} / \mathrm{cm}^{\circ} \mathrm{C}$ \\
& $\bullet \sim 100 \mu \mathrm{m}$ thickness \\
\hline
\end{tabular}

The anode structure is fabricated with a porosity of 20 to $40 \%$ to facilitate mass transport of reactant and product gases. Doped lanthanum Magnetite is most commonly used for the cathode material. Similar to the anode, the cathode is a porous structure that must permit rapid mass transport of reactant and product gases. The cell interconnection material (doped lanthanum Chromite), however, must be impervious to fuel and oxidant gases and must possess good electronic conductivity. In addition, the cell interconnection is exposed to both the cathode and anode environments thus, it must be chemically stable under $\mathrm{O}_{2}$ partial pressures of about $\sim 1$ to 
$10^{-18}$ atmospheres at $1000^{\circ} \mathrm{C}\left(1832^{\circ} \mathrm{F}\right)$. The solid oxide electrolyte must be free of porosity that permits gas to permeate from one side of the electrolyte layer to the other, and it should be thin to minimize ohmic loss. In addition, the electrolyte must have a transport number for $\mathrm{O}^{-}$as close to unity as possible, and a transport and a transport number for electronic condition as close to zero as possible. Zirconia-based electrolytes are suitable for SOFC's because they exhibit pure anionic conductivity over a wide range of partial pressures ( 1 to $10^{-20}$ atmospheres). The other cell components should permit only electronic conduction, and inter-diffusion of ionic species in these components at $1000^{\circ} \mathrm{C}\left(1832^{\circ} \mathrm{F}\right)$ should not have a major effect on their electronic conductivity. Other severe restrictions placed on the cell components are that they must be stable to the gaseous environments in the cell and that they must be capable of withstanding thermal cycling. The materials listed above appear to have the properties for meeting these requirements.

As with the other cell types, it is necessary to stack SOFC's to increase the voltage and power being produced. Because there are no liquid components, the SOFC can be cast into flexible shapes. As a result, the cell configurations can respond to other design prerequisites. This feature has resulted in two major configurations and variations of them. The predominant oxide fuel cell configuration at this time is tubular. This tubular configuration (i.e., cylindrical design) adopted for SOFC's minimizes the use of seals, especially in the highest temperature parts of the cell. Overlapping components (i.e., electrodes, electrolyte, cell interconnection) in thin layers $(10-50 \mu \mathrm{m})$ are deposited on a porous support tube of Calcia-stabilized Zirconia. The very high efficiency cycle uses a configuration that requires seals at the high temperature parts of the cells. An early tubular design is illustrated in the schematic representation of the cross section of a SOFC stack In this tubular design, individual fuel cells are arranged in bands along 
the support tube and are connected in series by a ceramic interconnect material. The seal-less tubular design, however, is the most advanced among the several SOFC configuration concepts.

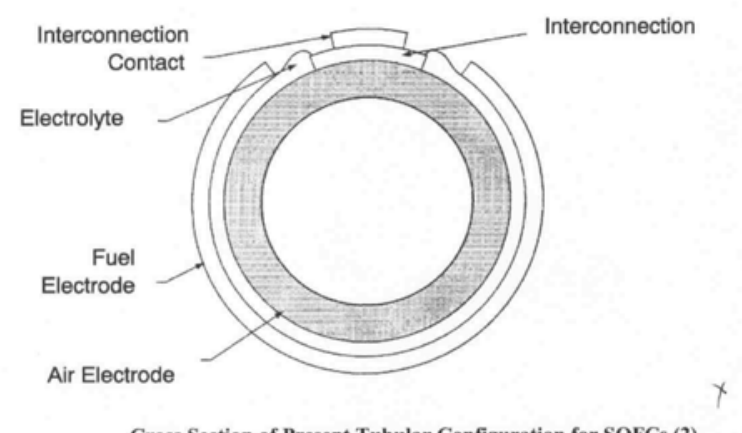

Cross Section of Present Tubular Configuration for SOFCs (2)

Seal-less Tubular Configuration: This approach results in eliminating seal problems between adjacent cells. A major advantage of this design over earlier designs is that relatively large single tubular cells can be constructed in which the successive active layers can be deposited without chemical or material interference with previously deposited layers. Materials and design approaches have been developed so that SOFC technology, particularly the tubular cell configuration, is technically feasible. However, the application of the materials used in the nonrestrained tubular cell to the restrained alternative planar configurations results in excessive mechanical stresses. Moreover, the present approaches exhibit lower than desired performance (higher operating costs) and difficult designs and fabrication (higher capital costs). Cost reduction of cell components and simplification of the manufacturing are an important focus of ongoing development. The major issue for improving SOFC technology is to develop materials that sustain good performance while withstanding the high operating temperature presently used $\left(1000^{\circ} \mathrm{C}\right)$, or to develop alternate cells with mixtures of ceramics and metals that operate at an 
intermediate temperature of approximately $650^{\circ} \mathrm{C}$. Two approaches are being pursued to alleviate the many materials and design concerns:

1) Research to address material and design improvements that allow operation within the high temperature environment $\left(1000^{\circ} \mathrm{C}\right)$ of the existing state-of-the-art components

2) Lowering the operating temperature $\left(600\right.$ to $\left.800^{\circ} \mathrm{C}\right)$, so that metals could be substituted for ceramics, especially in the cathode and interconnect. A wider variety of materials could be used with lower temperature operation, with a subsequent reduction in cost.

\section{High Temperature Cell Development (Present Operating Temperature, $1000^{\circ} \mathrm{C}$ )}

Development work for cells operating at $1000^{\circ} \mathrm{C}$ is focused on increasing the mechanical toughness of the cell materials to alleviate the impact of thermal mismatch and to develop techniques that will decrease interfacial changes of the various material layers during thin film cell fabrication. Interfacial issues among cell components include diffusion, volatization, and segregation of trace constituents. For example, $\mathrm{La}_{2} \mathrm{Zr}_{2} \mathrm{O}_{7}$ and $\mathrm{SrZrO}_{3}$ may form at the cathode/electrolyte interface, and $\mathrm{Sr}$ and $\mathrm{Mn}$ ions diffuse across the interface at temperatures as low as $800^{\circ} \mathrm{C}$ for up to 400 hours. Approaches to resolving the mismatch caused by different component materials' thermal expansion coefficient include increasing the fracture toughness of the electrolyte, controlling the electrolyte processing faults, varying the component thickness, and adding minor constituents to alter the anode properties. The electrolyte of choice at present is Yttria, fully stabilized $\mathrm{ZrO}_{2}$. Researchers are investigating partially stabilized $\mathrm{ZrO}_{2}$ and adding $\mathrm{Al}_{2} \mathrm{O}_{3}$ to fully Yttria stabilized $\mathrm{ZrO}_{2}$ to strengthen the electrolyte matrix. This increased strength is needed for self-supporting planar cells. An increase in bending strength of $1200 \mathrm{MPa}$ was 
observed in the TZP material compared to $300 \mathrm{MPa}$ for cubic zirconia stabilized with $>7.5$ mol\% $\mathrm{Y}_{2} \mathrm{O}_{3}$. The TZP was stabilized by taking advantage of fine particle technology and minor doping of $\mathrm{Y}_{2} \mathrm{O}_{3}$

\section{Scientific Discussion}

A broad program for resolution of the material and component issues prior to integration into a fuel cell require a research program to address various issues such as:

1) Magnitudes of ionic and electronic conduction,

2) Thermal expansion issues for compatibility with other cell components,

3) Phase stability in the fuel cell environment,

4) Mechanical strength,

5) Chemical interactions with the electrode materials, and

6) Stability of ionic conduction in reducing and oxidizing environments.

In addressing the structural issues of the cell it is essential to have a detailed knowledge of constitutive behavior of monolith and composite structures (ex: electrolyte materials over porous electrodes etc.). Along with functional aspects such as conductivity etc., issues such as mechanical integrity, long-term performance, and stability in a reducing environment, are of paramount importance. The various subtleties in the process conditions and its effect on the fuel cell materials structural properties are not entirely understood and have been a fertile area for research. There are also no definitive studies on the long term behavior of fuel cell materials at high temperatures and under severe reducing conditions/oxygen gradients. Specifically, it is important to be able to predict long-term behavior of fuel cells using short term and accelerated tests. However, experimental and reliable data on the materials behavior in the application environment are few or severely lacking. The results from the proposed study thus intend to provide important inputs for the design of fuel cell by characterization of material components in various environments. 


\section{Task 1.2.1 Determination of Crack Growth Parameters}

\section{A) YSZ characterization:}

Yttria stabilized Zirconia (YSZ) of $9.6 \mathrm{~mol} \%$ Yttria composition were procured in the form of tubes of length $100 \mathrm{~mm}$. The tubes were processed by slip casting and are of the dimensions 9.6 O.D and wall thickness of $\sim 1-1.2 \mathrm{~mm}$. Rings were cut from the tubes and characterized for microstructure, phase stability and mechanical strength.

\section{Microstructure:}

The YSZ rings were ground and polished to $0.25 \mu \mathrm{m}$ finish. The polished sample were thermally etched at $1400^{\circ} \mathrm{C}$ for 2 hours and observed under an optical microscope.

Microstructural analysis indicated a dense and equi-axial grain size of $\approx 15 \mu \mathrm{m}$. Isolated porosity were observed at triple grain boundary points. Micro pores in the grain were closed and did not contribute to the porosity.

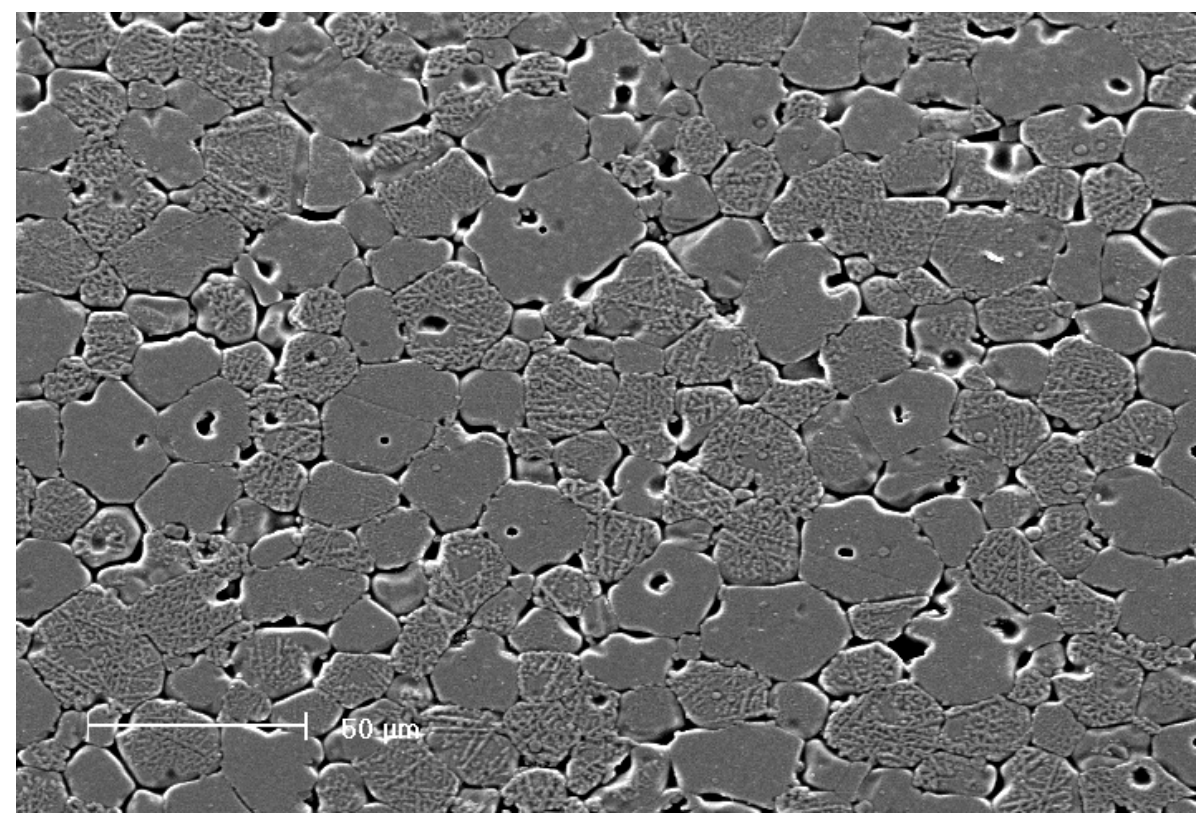

Figure 1: a) Optical micrograph of the thermally etched YSZ indicating uniform grain size. 


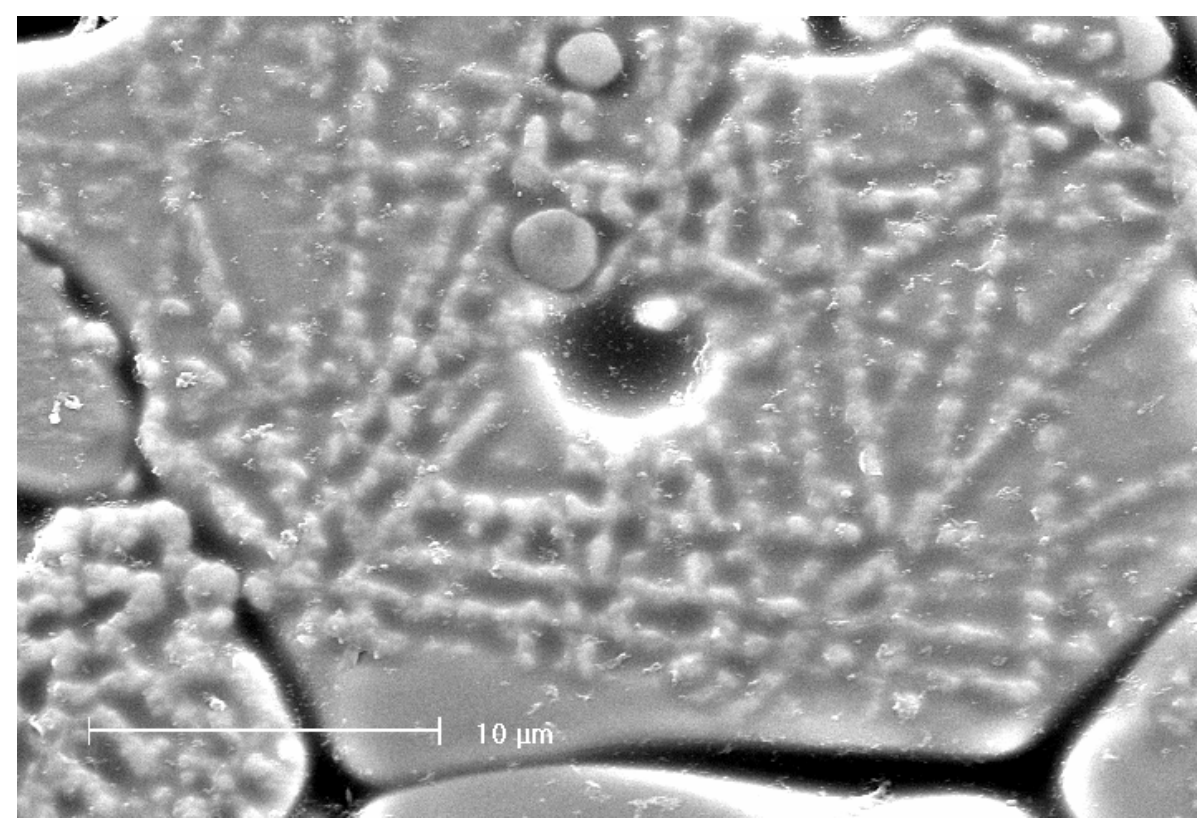

Figure 1: b) Higher magnification of a single grain of the thermally etched YSZ indicating closed porosity in the grain

The YSZ tubes were analysed for phase stability. The X-ray analysis as shown in figure 2, indicated full stabilization of the YSZ structure with the Yttria composition.

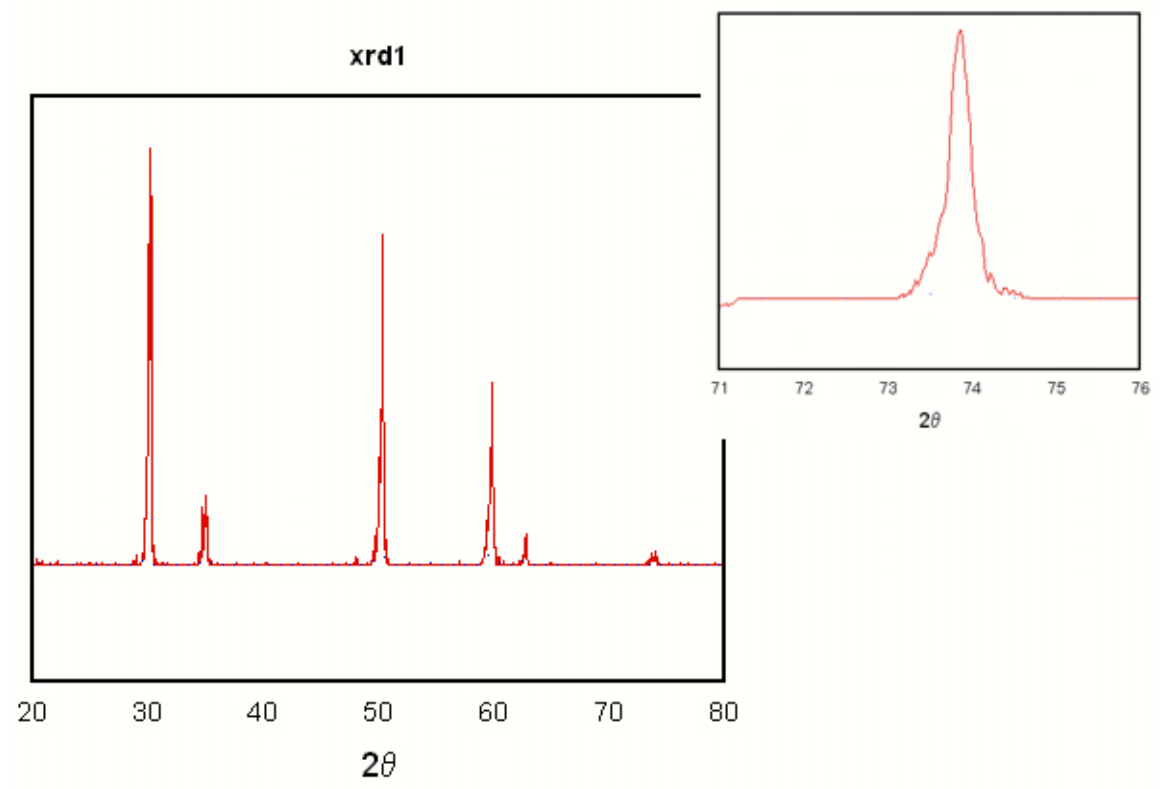

Figure 2: $\quad$ X-ray analysis of the YSZ tube indicating full stabilization of the cubic phase. 


\section{Mechanical Testing:}

The YSZ tubes were sliced into rings and the strength of the rings was determined according to ASTM C 1323 - 96 (Standard test method for ultimate strength of advanced ceramics with diametrally compressed C-Ring specimens at ambient temperature). Rings of length $\sim 4.4 \mathrm{~mm}$ were cut from the tubes in a low speed saw. The surfaces of the rings were ground and polished to a $1 \mu \mathrm{m}$ finish using successive grades of $\mathrm{SiC}$ paper and finally with a diamond compound. The edges of the rings were chamfered to minimize preferential failures from edge flaws and notched by a $0.5 \mathrm{~mm}$ low speed saw to form a C-ring specimen. The C-rings were placed in an autoclave (to ensure uniform temperature and humidity) between two alumina platens in a hydraulic testing frame (MTS 858 MiniBionix II). Stabilized Zirconia cloth $(0.5 \mathrm{~mm})$ was used as pressure pads to reduce frictional stresses and to prevent slippage of the rings during testing (Fig. 1). All the tests were done by monotonically loading in plane strain diametral compression (induces a tensile field at the mid plane) to fracture at a constant crosshead speed of $1 \mathrm{~mm} . / \mathrm{min}$. The maximum fracture strength of the C-Ring specimens were calculated from the equation

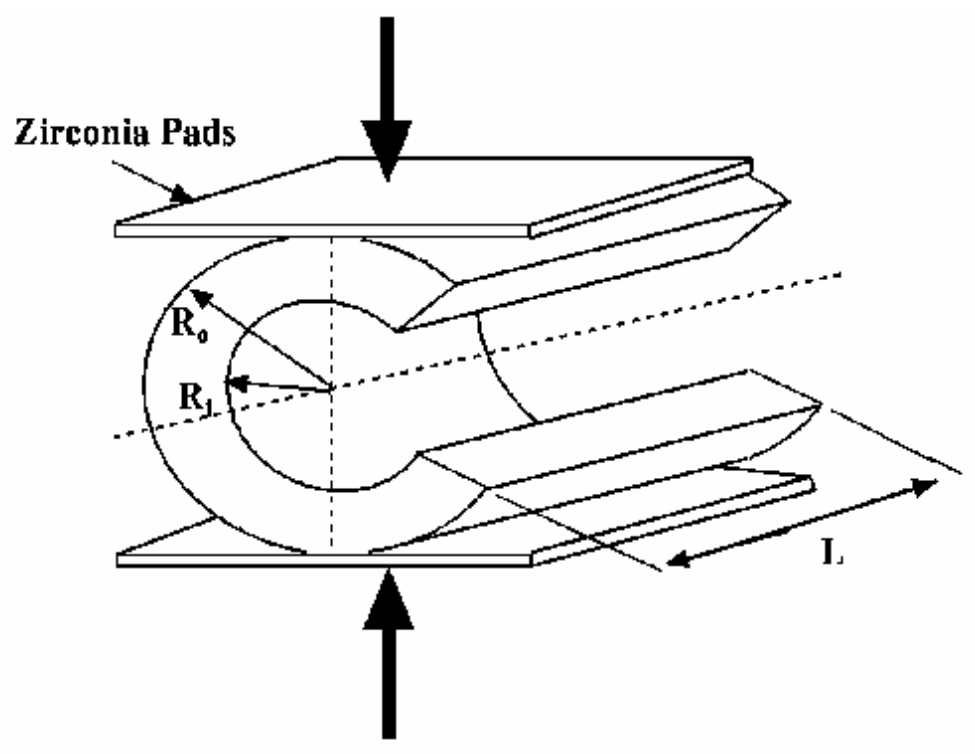

Figure 3: $\quad$ C-ring test configuration for strength evaluation of YSZ tubes 
Where $r_{o}$ - is the outer radius of the C-Ring, $b$ - the width of the ring, $t$ - thickness and $P$ the fracture load. However, the actual fracture strength is calculated from the measure angle of fracture from the mid plane.

$$
\sigma_{\theta \max }=\frac{P R}{b t r_{o}}\left[\frac{r_{o}-r_{a}}{r_{a}-R}\right]
$$

A total of 12 rings were evaluated and the results plotted as a Weibull graph. For this the sample were ranked in a ascending order of their measured strength. The failure probability was determined according to:

$$
F=\frac{n-\left(\frac{1}{2}\right)}{N}
$$

Where $F$ is the failure probability, $n$ is the order of ranking and $N$ is the total number of samples tested.

The results were analyzed in a parameter Weibull distribution, where $m$ is the modulus and $\sigma_{\mathrm{o}}$ is the characteristic strength. The parameter $m$ in ceramics gives a measure of the strength distribution with a higher value denoting higher reliability.

$$
F=1-e^{-\int\left(\frac{\sigma}{\sigma_{o}}\right)^{m} d v}
$$




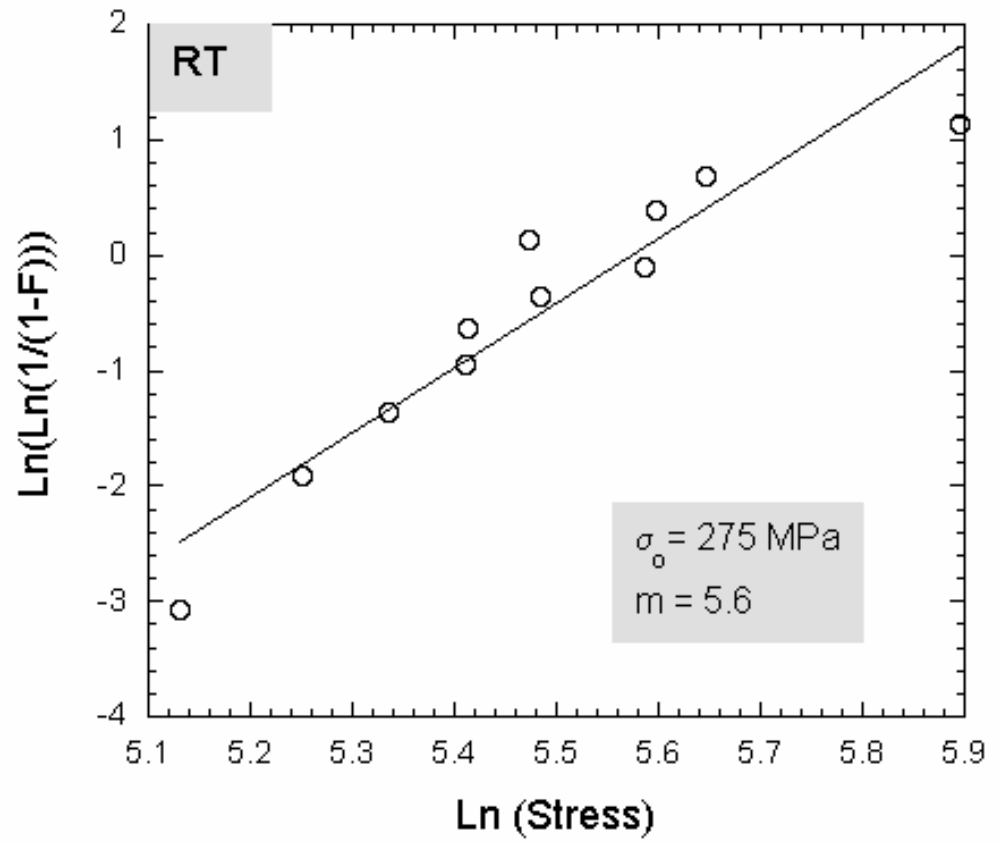

Figure 4: Weibull plot for strength evaluation of YSZ tubes at room temperature

The Weibull modulus for the YSZ tubes was determined as 5.6 and $\sigma_{\mathrm{o}}$ as $275 \mathrm{MPa}$. A detailed examination of the fractured surfaces will be important in characterizing the flaws and fracture origins to complete the study at room temperature.

\section{Slow Crack Growth Tests:}

The YSZ tubes were sliced into rings and the strength of the rings was determined according to ASTM C 1323 - 96 (Standard test method for ultimate strength of advanced ceramics with diametrally compressed C-Ring specimens at ambient temperature). Rings of length $\sim 4.4 \mathrm{~mm}$ were cut from the tubes in a low speed saw. The surfaces of the rings were ground and polished to a $1 \mu \mathrm{m}$ finish using successive grades of $\mathrm{SiC}$ paper and finally with a diamond compound. The edges of the rings were chamfered to minimize preferential failures from edge flaws and notched by a $0.5 \mathrm{~mm}$ low speed saw to form a C-ring specimen. The C-rings were placed in an autoclave (to ensure uniform temperature and humidity) between two alumina platens in a hydraulic testing 
frame (MTS 858 MiniBionix II). Stabilized Zirconia cloth $(0.5 \mathrm{~mm})$ was used as pressure pads to reduce frictional stresses and to prevent slippage of the rings during testing (Fig. 1). All the tests were done by monotonically loading in plane strain diametral compression (induces a tensile field at the mid plane) to fracture. Tests for evaluation of slow crack growth parameters were done in accordance with ASTM designation C 1368-97 and in plane strain conditions. The applied strain rates were calculated from the specimen geometry (ASTM C 1323-96) and the strength tests done in displacement control at a constant crosshead speed of $0.035,0.3,1$ and 2.5 $\mathrm{mm} . / \mathrm{min}$. according to the test standard, five samples were tested at each strain rate. The maximum fracture strength of the C-Ring specimens were calculated from the equation

$$
\sigma_{\theta \max }=\frac{P R}{b t r_{o}}\left[\frac{r_{o}-r_{a}}{r_{a}-R}\right]
$$

In very low speed tests $(0.035 \mathrm{~mm} / \mathrm{min})$, the time required for testing was minimized by applying a preload to the test specimen prior to testing. The preloads were approximately 0.5 times the fracture loads at that stress rate. The fracture strengths determined in this case was not observed to show any significant change.

Results of the strength tests at different crosshead speeds are reported in Table 1. The actual stress rates were calculated from the slope in the load vs. displacement curves of the individual strength tests in accordance with ASTM C 1368-97.

Table 1: $\quad$ Strength values of YSZ tubes at varying stress rates

\begin{tabular}{|c|c|c|c|}
\hline Specimen No & $\begin{array}{c}\text { Cross-head } \\
\text { Speeds, } \mathrm{mm} / \mathrm{min}\end{array}$ & $\begin{array}{c}\text { Stress Rates, } \\
\mathrm{MPa} / \mathrm{s}\end{array}$ & $\begin{array}{c}\text { Fracture strength, } \\
\mathrm{MPa}\end{array}$ \\
\hline 1 & 0.035 & 0.47604 & 181.92 \\
\hline 2 & 0.035 & 0.41663 & 130.46 \\
\hline 3 & 0.035 & 0.43918 & 194.06 \\
\hline
\end{tabular}




\begin{tabular}{|c|c|c|c|}
\hline 4 & 0.035 & 0.43956 & 192.85 \\
\hline 5 & 0.035 & 0.49566 & 170.21 \\
\hline 6 & 0.3 & 4.9393 & 206.43 \\
\hline 7 & 0.3 & 4.4950 & 197.04 \\
\hline 8 & 0.3 & 4.3665 & 222.55 \\
\hline 9 & 0.3 & 4.0640 & 166.03 \\
\hline 10 & 0.3 & 4.4046 & 224.38 \\
\hline 11 & 1 & 30.539 & 240.67 \\
\hline 12 & 1 & 30.300 & 270.05 \\
\hline 13 & 1 & 31.506 & 266.79 \\
\hline 14 & 1 & 31.448 & 283.16 \\
\hline 15 & 1 & 32.141 & 363.44 \\
\hline 16 & 2.5 & 53.066 & 213.95 \\
\hline 17 & 2.5 & 53.473 & 189.72 \\
\hline 18 & 2.5 & 51.343 & 176.95 \\
\hline 19 & 2.5 & 56.633 & 202.83 \\
\hline 20 & 2.5 & 50.528 & 161.96 \\
\hline
\end{tabular}

The strength values of the YSZ tubes decreased with decreased applied test rates. This behaviour is expected, as at lower stress rates, the strength is probably affected by sub-critical growth of cracks. The strength value at higher stress rates is however anomalous, since a drop in strength values were observed. This observed drop in strength could not be further verified as testing at higher stress rates were not possible in the present experimental set up. A detailed analysis of fracture surfaces could possibly provide clues to the observed effects.

The results of the strength tests as a function of stress rates are plotted in Fig 5. The plots are conventionally represented as a plot of Log (Fracture Strength) versus Log (Stress Rates) as shown in Fig $5 b$. 

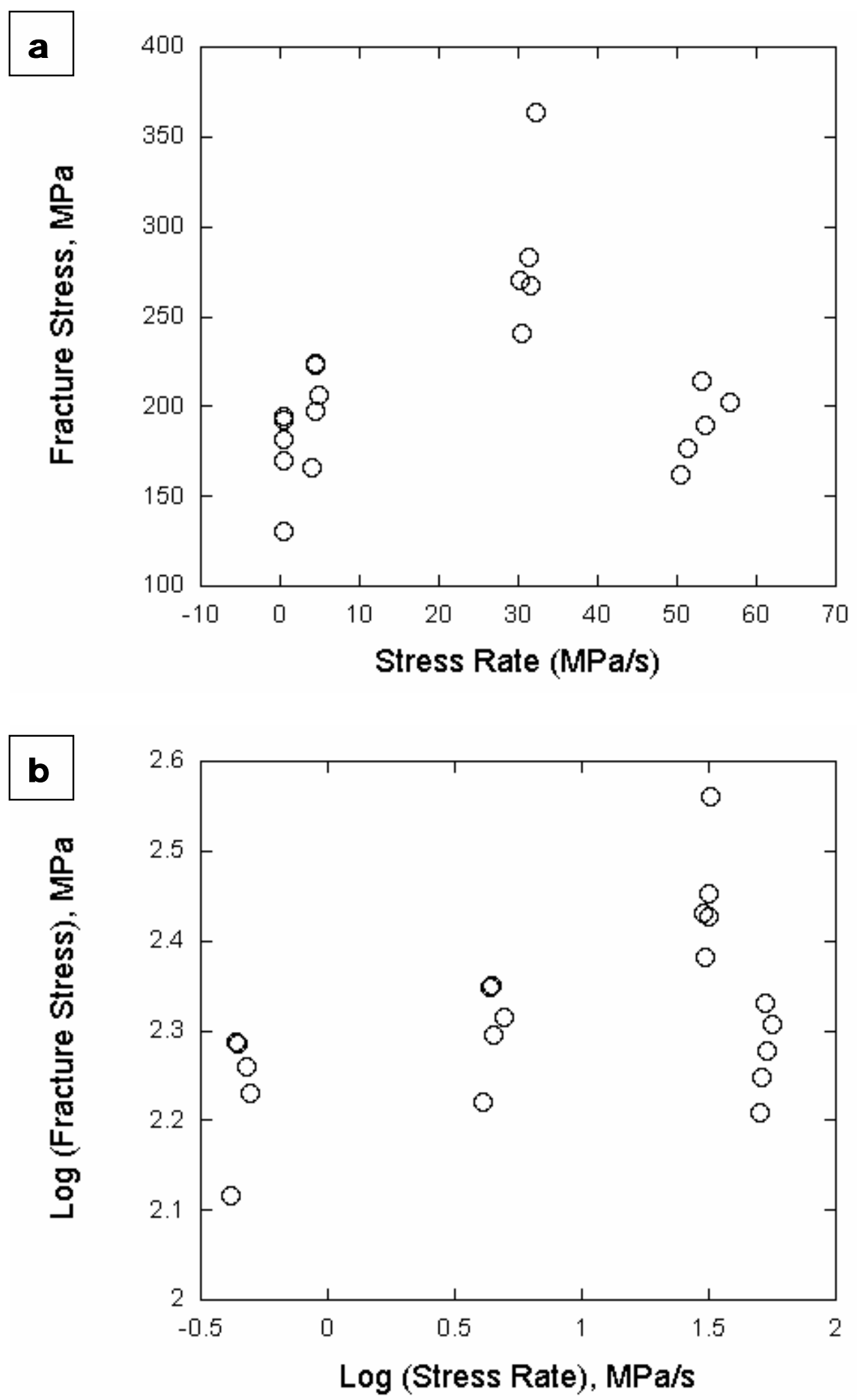

Fig. 5 C-ring Fracture Strength-Stress Rate Diagram. a) Plot of strength vs. stress rate and b) Log (Fracture Strength) versus Log (Stress Rate) 


\section{Fracture analysis:}

The tested samples were sputtered with gold and observed in a SEM for study of fracture. Fracture was observed to be dominated from flaws originating from the surface. Although, volume pores were observed in the fractured surfaces, their contribution to the fracture processes was not significant.

Fracture in the YSZ material was by brittle trans-granular mode. The grains indicated presence of micro-cleavage planes. Micro-cleavage planes were significantly higher in specimens fracture at lower stress rates (Fig 2 a and b) indicating sub critical crack growth in the grains. At a stress rates of $30 \mathrm{MPa} / \mathrm{s}$ (Fig $2 \mathrm{c}$ and d), the specimens indicated less roughness and reduced cleavage planes. Specimen fractured at higher stress rates are to analysed to study the reason for drop in strength.
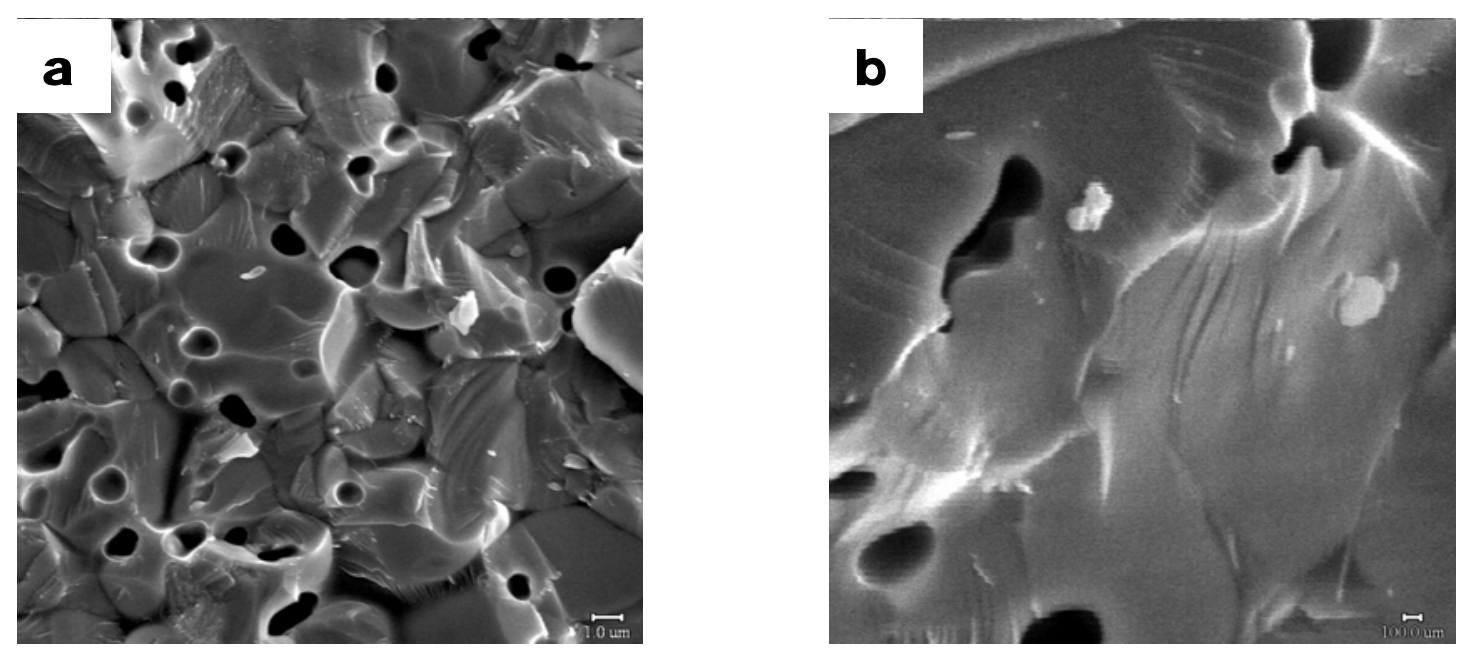

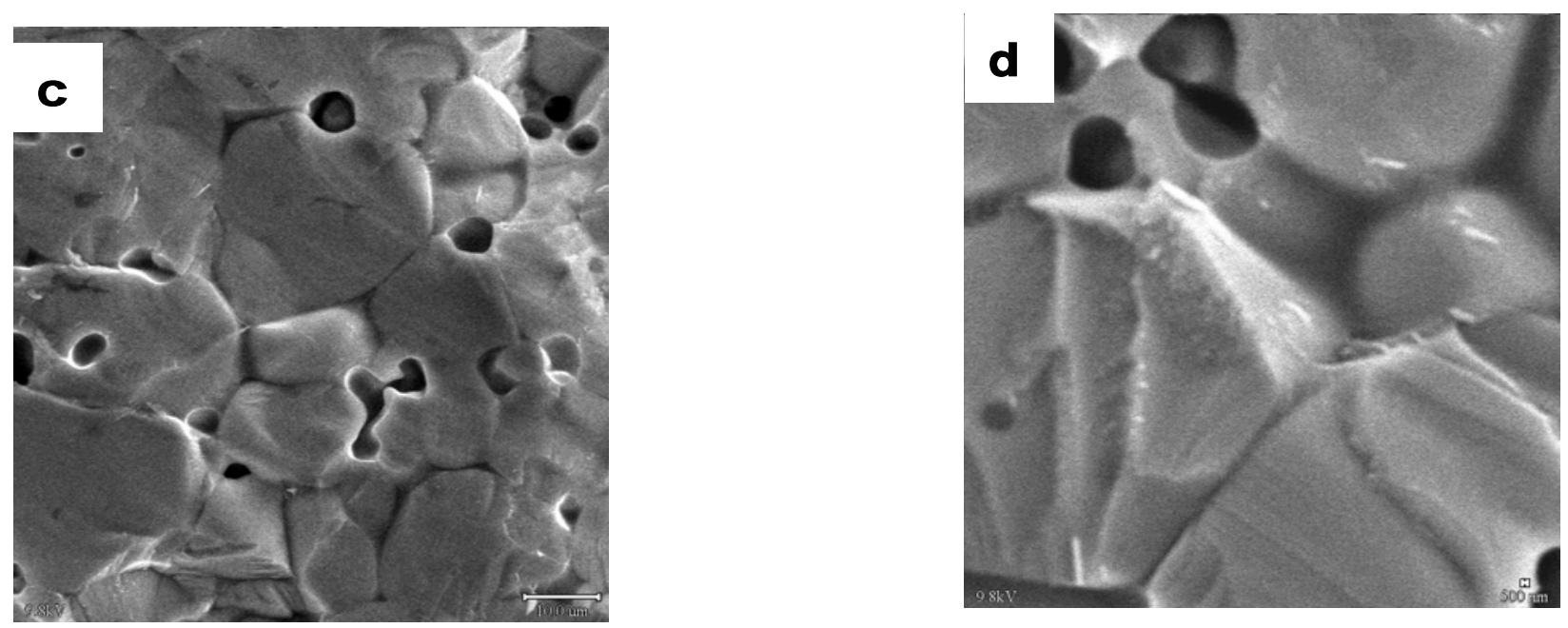

Fig. 6 Fracture surfaces examined under SEM indicating transgranular fracture. At low stress rates ( $a$ and $b$ ), higher incidence of micro-cleavage in grains in visible. At higher stress rates $(50 \mathrm{MPa} / \mathrm{s})$, grains are relatively smoother with reduced microcleavage planes.

\section{Slow Crack Growth Analysis}

The ASTM test method C-1368, specifically deals with characterising ceramic materials with susceptibility to slow crack growth (SCG). SCG may e a product of both mechanical and chemical driving process. The present report is on the room temperature behaviour and the only consideration is the mechanical driving force. Latter studies will concentrate on the chemical driving forces (gas atmosphere and temperature).

The SCG parameters $n$ and $D$ can be determined by a linear regression analysis using $\log$ strength values over the complete range of individual log stress rates, based on the following equation.

$$
\log \sigma_{f}=\frac{1}{n+1} \log \dot{\sigma}+\log D
$$

The slope of the linear regression line can be calculated as: 


$$
\alpha=\frac{K \sum_{j=1}^{K}\left(\log \dot{\sigma}_{j} \log \sigma_{j}\right)-\left(\sum_{j=1}^{K} \log \dot{\sigma}_{j} \sum_{j=1}^{K} \log \sigma_{j}\right)}{K \sum_{j=1}^{K}\left(\log \dot{\sigma}_{j}\right)^{2}-\left(\sum_{j=1}^{K} \log \dot{\sigma}_{j}\right)^{2}}
$$

Where $\alpha=$ slope, $\mathrm{K}$ is the total number of specimens tested $(=20), \sigma_{j}$ and $\sigma_{j}$ is the stress rate and fracture strength of the individual test specimen respectively.

The SCG parameter $\mathrm{n}$ is calculated as

$n=(1 / \alpha)-1$

The intercept of the linear regression line is calculated as

$$
\beta=\frac{\left(\sum_{j=1}^{K} \log \sigma_{j}\right) \sum_{j=1}^{K}\left(\log \dot{\sigma}_{j}\right)^{2}-\left(\sum_{j=1}^{K} \log \dot{\sigma}_{j} \log \sigma_{j}\right)\left(\sum_{j=1}^{K} \log \dot{\sigma}_{j}\right)}{K \sum_{j=1}^{K}\left(\log \dot{\sigma}_{j}\right)^{2}-\left(\sum_{j=1}^{K} \log \dot{\sigma}_{j}\right)^{2}}
$$

Where $\beta$ is the intercept and the SCG parameter D is calculated as $D=10^{\beta}$

From the above calculations, the SCG parameter for the YSZ tubes at room temperature under constant humidity was calculated as $n=16.6$ and $D=184.74$. Fitting these values in equation 2 , it is possible to calculate the strength values at various loading rates, typically of static fatigue conditions.

The values of $n=16.6$ implies a low susceptibility to SCG at room temperature. Typically, if a ceramic materials exhibits a high susceptibility the values of $n$ would be lesser than 5 . 


\section{Elevated Temperature studies:}

\section{$\underline{A I R}$}

Results of the strength tests at elevated temperature are reported in Table 1. As shown below, the strength of the YSZ tubes degraded significantly upon exposure to test condition of $1000^{\circ} \mathrm{C}$ in air. A maximum of $134 \mathrm{MPa}$ corresponded to $37 \%$ of the strength observed at room temperature.

Table 2: $\quad$ Strength values of YSZ tube at $1000^{\circ} \mathrm{C}$ in air.

\begin{tabular}{|l|l|l|}
\hline Test Condition & Air, RT & Air, $1000^{\circ} \mathrm{C}$ \\
\hline No of Samples & 11 & 11 \\
\hline Minimum Strength & $97 \mathrm{MPa}$ & $73.4 \mathrm{MPa}$ \\
\hline Maximum Strength & 363.4 & $134.3 \mathrm{MPa}$ \\
\hline Mean Strength & 231.3 & $95.4 \mathrm{MPa}$ \\
\hline
\end{tabular}

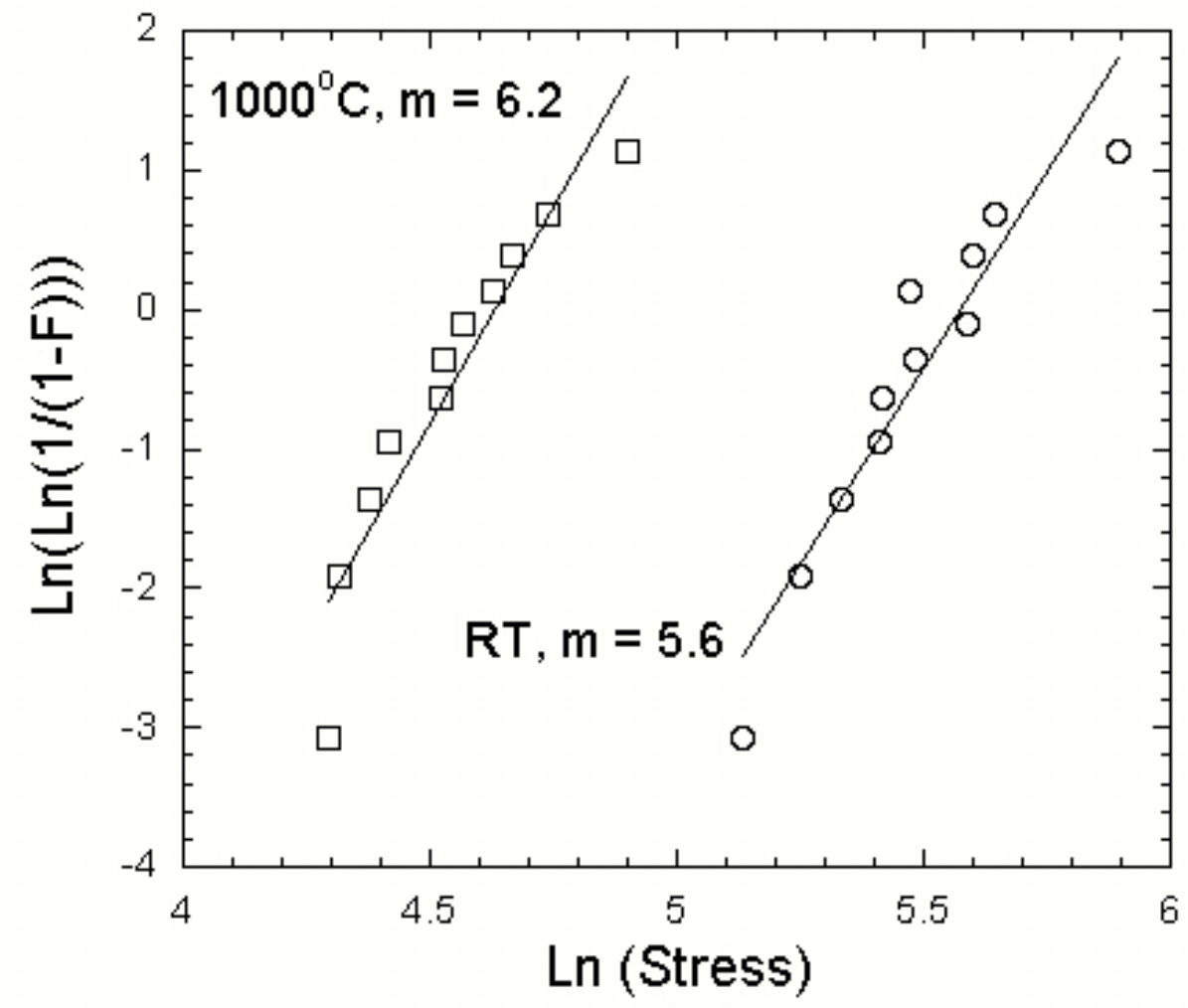

Fig. 7: $\quad$ Weibull plots of C-ring fracture strength at room temperature and at $1000^{\circ} \mathrm{C}$ in air. 
The strength values plotted as Weibull distribution was similar to data of that of room temperature. However, a slight increase in Weibull modulus, m, from 5.6 to 6.2. Although, the change is not significant, there are possibilities of change in flaw distribution upon exposure to elevated temperature. Macroscopic observation indicated roughening of outer and fracture surfaces of the YSZ tubes. Microscopic and SEM studies should reveal more information on the strength controlling flaws and their influence on measured strength. 


\section{CONCLUSIONS}

Yttria stabilized Zirconia with $9.6 \%$ mol composition of Yttria exhibited reasonable strength but with low Weibull Modulus 'm'. In air at $1000^{\circ} \mathrm{C}$, the strength of the YSZ component was reduced to less $50 \%$. However the Weibull modulus of the YSZ remains relatively unchanged. The SCG parameter for the YSZ tubes at room temperature under constant humidity was calculated as $n=16.6$ and $D=184.74$ and implied a low susceptibility to SCG at room temperature. SEM analysis of failed C-rings indicated flaws originating from the surface and crack progressing transgranularly as the primary mode of fracture as. At low stress rates higher incidence of micro-cleavage in grains in visible as compared to grains failing at higher stress rates $(50 \mathrm{MPa} / \mathrm{s})$. The higher incidences of micro-cleavage planes are due to the slow crack growth in the YSZ specimens. 